\title{
Commentary: E-cigarettes and the thoracic surgeon, friend or foe?
}

\section{Waël C. Hanna, MDCM, MBA, FRCSC}

In this invited article, ${ }^{1}$ Dr Steliga takes on the complex and challenging topic of smoking cessation. This excellent work addresses many of the challenges that we face when advocating for cessation, especially when it comes to questions about e-cigarettes. If there is one piece of literature on the topic that you will read this year, this should be it.

Dr Steliga first acknowledges our inadequate efforts to get patients to quit smoking. I am guilty, as are you, probably, of spending far too much time talking about treatment of lung cancer and far too little time talking about prevention. Conventional wisdom would have it that prevention is the best form of cure, but for some reason, we don't prioritize this conversation with our patients. The emergence of e-cigarettes has ignited (no pun intended) a new conversation around the topic. For the first time ever, smokingcessation conversations are actually initiated by patients when they seek advice about e-cigarettes. Data show that most of them view the e-cigarettes favorably-a cool invention that addresses the puffing habits and the social aspects of smoking, all the while offering an opportunity to quit a cancer-causing addiction. Suddenly, the conversation around smoking cessation takes a new tone; it is transformed from a guilt-tripping session about the harms of smoking into a conversation about perhaps a lesser of 2 evils alternative. The popularity of e-cigarettes presents an opportunity for us to change the narrative about cessation, without stigma or blame. In that sense, one can look at e-cigarettes as a friend in the fight.

However, e-cigarettes also have their share of harmful health hazards. Lack of regulation, poor long-term data,

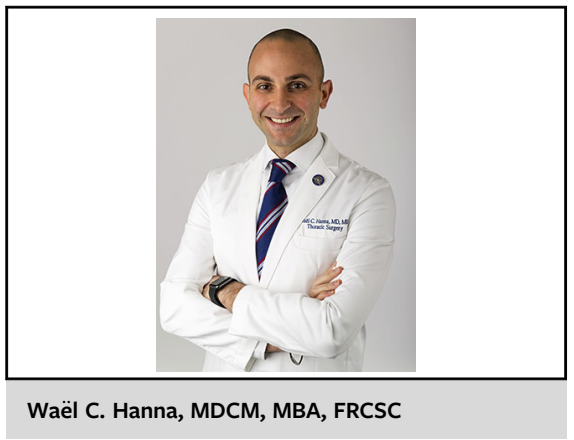

CENTRAL MESSAGE

E-cigarettes have transformed

the conversation about smoking

cessation, and thoracic surgeons

have an important part to play in

the discussion.

reports of serious lung and bodily injury, the recruitment of tobacco naive nonsmokers into the habit, and the paucity of convincing data about their effectiveness in cessation are a few serious drawbacks discussed in this article. In that sense, one can look at e-cigarettes as a foe in the fight.

So, are e-cigarettes friends or foes of thoracic surgeons? Dr Steliga seems to suggest that only time will tell. Until the jury is out, we need to do our part and become involved in the conversation. If the e-cigarette debate achieves only that, then it is a friend in my opinion.

\section{Reference}

1. Steliga MA. Health hazards of electronic cigarettes and their utility in smoking cessation. J Thorac Cardiovasc Surg. 2022;163:307-10.

\footnotetext{
From the Division of Thoracic Surgery, McMaster University, Hamilton, Ontario, Canada.

Disclosures: The author reported no conflicts of interest.

The Journal policy requires editors and reviewers to disclose conflicts of interest and to decline handling or reviewing manuscripts for which they may have a conflict of interest. The editors and reviewers of this article have no conflicts of interest.

Received for publication Dec 4, 2020; revisions received Dec 4, 2020; accepted for publication Dec 5, 2020; available ahead of print Dec 19, 2020.

Address for reprints: Waël C. Hanna, MDCM, MBA, FRCSC, St Joseph's Healthcare Hamilton, 50 Charlton Ave E, Juravinski Tower, Suite T2105 F, Hamilton, ON, L8N4A6 (E-mail: hannaw@mcmaster.ca).

J Thorac Cardiovasc Surg 2022;163:312

$0022-5223 / \$ 36.00$

Copyright (c) 2020 by The American Association for Thoracic Surgery

https://doi.org/10.1016/j.jtcvs.2020.12.040
} 